\title{
Comparisons of Social Support and Social Networks in Homeless and Vulnerably Housed Women
}

\author{
Stephanie Rattelade \\ University of Ottawa \\ Susan Farrell \\ Royal Ottawa Health Care Group and University of Ottawa
}

\begin{abstract}
Social support is closely connected to mental health and well-being as well as experiences of housing vulnerability. This study explored differences between homeless and vulnerably housed women in their experiences of social support. Forty-nine homeless and 43 vulnerably housed women completed 3 measures to assess their social networks, social support networks, and global social support. Vulnerably housed women reported fewer social support network members than homeless women. Social support network size was found to be a predictor of global social support score. These findings suggest that housing status impacts social support in homeless and vulnerably housed women, which may have implications for their well-being.
\end{abstract}

Keywords: social support, social networks, homelessness, housing vulnerability, women

\section{RÉSUMÉ}

Le réseau social est associé avec la santé mentale et le bien-être, ainsi que les expériences de l'itinérance et de la vulnérabilité du logement. Cette étude expérimentale explore les différences entre les femmes sansabri et les femmes dont le logement est précaire («femmes mal logées») ainsi que leurs expériences avec le réseau social. Quarante-neuf femmes sans-abri et quarante-trois femmes mal logées ont complété trois sondages pour évaluer leurs réseaux sociaux. Les femmes mal logées interagissent avec moins de membres du réseau social que les femmes sans-abri. La taille du réseau social est un indicateur du résultat global

Stephanie Rattelade, School of Psychology, Faculty of Social Sciences, University of Ottawa, Ontario; Susan Farrell, Royal Ottawa Health Care Group, Department of Psychiatry, Faculty of Medicine, and Faculty of Social Sciences, University of Ottawa, Ontario.

Stephanie Rattelade is now in the Programs Department at The Ottawa Mission, Ottawa, Ontario.

This research was supported by funding through the School of Political Studies, University of Ottawa. This publication is based on research conducted as part of a completed dissertation entitled "The Exploration of Social Support and Social Networks in Homeless and Vulnerably Housed Women." The completed dissertation can be found at https://ruor.uottawa.ca/handle/10393/34352

Correspondence concerning this article should be addressed to Stephanie Rattelade, Programs Department, The Ottawa Mission, 35 Waller St., Ottawa, ON K1N 7G4. Email: srattelade@ottawamission.com 
du réseau social. Les résultats indiquent que l'endroit du logement influence le réseau social des femmes sans-abri et mal logées, qui ont des conséquences sur leur bien-être.

Mots clés : soutien social, réseaux sociaux, itinérance, vulnérabilité du logement, femmes

Women place more emphasis on their social relationships than men, relying on them to cope with stressful situations (Haines, Beggs, \& Hurlbert, 2008). Social support has been shown to reduce stress, symptoms of anxiety, mental illness, distress, and improve overall well-being in various populations (Durden, Hill, \& Angel, 2007; Israel, Farquhar, Schulz, James, \& Parker, 2002; Tucker, D’Amico, Wenzel, Golinelli, Elliott, \& Williamson, 2005; Turner, Murmelstein, Hitsman, \& Warneke, 2008). Research has continued to show that social support can help buffer the effects of stressful life events and crises (Thoits, 2010). With the stresses that homelessness and housing vulnerability create, social support becomes even more important for women to buffer the negative effects of day-to-day stressors. Exploring social networks and the levels of social support in low-income women can highlight potential deficits in social support and suggest areas in which support may be needed to help reduce stress and increase well-being in difficult housing situations.

\section{HOMELESSNESS AND HOUSING VULNERABILITY}

Homelessness is a complex concept that describes individuals without a home and is influenced by systemic, societal, and individual factors (Canadian Homelessness Research Network, 2012). Vulnerably housed individuals are currently in housing but are at high risk for losing their housing due to unaffordability, overcrowding, or unsafe conditions. Previous experiences of homelessness also increase the risk of future homeless episodes, adding those previously homeless to the vulnerably housed population (Hwang et al., 2011; McQuistion, Gorroochurn, Hsu, \& Caton, 2014). Housing is a key social determinant of health; housing vulnerability and homelessness have been linked to physical and mental illness, assaults and injuries, and mortality (Aubry, Klodawsky, Hay, \& Birnie, 2003; Hwang et al., 2011). Single women account for 15-30\% of the homeless population and are considered more vulnerable than men as they are more likely to choose support and services that keep them hidden from mainstream society (Alliance to End Homelessness [ATEH], 2016; Gaetz, Gulliver, \& Richter, 2014; Novac, Brown, \& Bourbonnais, 1996; Segaert, 2012). Women are more likely to use informal strategies to find housing, such as couch surfing and attaching to housed men, making them less visible on the streets and to formal homelessness services (Klodawsky, 2006).

It has been suggested that homeless and vulnerably housed groups are overlapping populations with similar experiences and challenges (Hwang et al., 2011). Hwang et al. (2011) found similarly high rates of illness, hospital use, and mortality regardless of their current housing situation. This study suggested that housing status is dynamic, with the same group of individuals experiencing frequent transitions between housing and homelessness. However, studies of women's housing experiences often compare homeless women to stably housed individuals, examining two very different populations (Anderson \& Rayens, 2004; Goodman, 1991; Toohey, Shinn, \& Weitzman, 2004). Studying vulnerably housed populations can provide valuable insight into the differences among experiences of homelessness, vulnerably housed, and stable housing. Specifically, studying the dissimilarities between vulnerably housed and homeless individuals may offer 
evidence about how changes in housing can impact social relationships and may suggest new approaches to preventing and ending homelessness. Previous studies have used this logic and compared these populations with respect to various characteristics and life experiences (e.g., Lyon, Dooley, \& Gagnon, 2014). In order to understand how housing is connected to social relationships in women, there is a need for comparisons of different types of housing experiences.

\section{HOUSING VULNERABILITY AND SOCIAL RELATIONSHIPS}

Previous research has shown that women's housing experiences intersect with their social relationships (Bui \& Morash, 2010; Cheng et al., 2013; Cohen, Ramirez, Teresi, Gallagher, \& Sokolovsky, 1997; Karabanow, 2008; Tessler, Rosenheck, \& Gamache, 2001). Interpersonal conflict and a lack of instrumental support were reported within the top three reasons women became homeless (Tessler et al., 2001). The quality as well as presence or absence of social relationships can influence housing options and contribute to both entering and exiting homelessness (Cheng et al., 2013; Cohen et al., 1997; Karabanow, 2008; Tessler et al., 2001).

The qualitative literature has also reported a connection between housing and social relationships. Klitzing (2004) found that half of the women reported friendships exclusively with others staying at the shelter, limiting their ties with individuals outside their current housing situation. Furthermore, studies have shown that changes in housing, such as moving to a new neighbourhood or exiting homelessness can impact social relationships and access to social support (Bui \& Morash, 2010; Curley, 2009; Kleit, 2010; Karabanow, 2008).

The social support literature suggests that homeless women have lower social support than housed women (Anderson \& Rayens, 2004; Kennedy, 2007; Toohey et al., 2004; Votta \& Farrell, 2009). However, the social network literature shows conflicted findings. One study found that homeless young women had smaller social networks than housed young women (Tavecchio, Thomeer, \& Meeus, 1999); another study suggested that homeless mothers had larger social networks compared to housed mothers (Shinn, Knickman, \& Weitzman, 1991). A third study found no difference in homeless and housed mothers' social network composition or size (Goodman, 1991). Although these studies consider different subpopulations, the uncertainty in these findings suggest a need for clarification with respect to housing and social networks. Furthermore, these studies examine differences between homeless and stably housed individuals. Comparing homeless and vulnerably housed women will provide evidence specific to experiences of housing vulnerability and its impact on social support.

\section{THE LINK BETWEEN SOCIAL NETWORKS AND SOCIAL SUPPORT}

Although separate constructs, social support and social networks overlap in their definitions and measurement. Social networks are the group of individuals that a person regularly interacts with and are often defined by their descriptive characteristics, such as size, density, and proximity. In contrast, social support offers information about the quality of the relationship and the supportive behaviours that are exchanged between two individuals. However, measures of social support often merge the two constructs, using social network characteristics to explain social support (Brenner, Norvell, \& Limacher, 1989; Tyler, 2008). This overlap adds further confusion and inaccuracy when measuring these two concepts. 
For example, social support networks are measured in many studies (Barrera, 1980; Sarason, Levine, Basham, \& Sarason, 1983). Social support networks are specific to the networks of individuals who are perceived to provide support. This type of network is separate from social support as it only measures the people who offer support and not the quality or other aspects of support from those relationships. It is also set apart from other social networks, as it focuses specifically on network members that provide support. Social support networks can provide important information about the perceived availability of social support; however, many of these studies equate social support networks as measures of social support, failing to account for this distinction.

Despite the differences between social networks and social support, social network characteristics may provide information that can help understand social support. Stokes (1983) found a positive linear relationship between social network size and social support satisfaction. However, he also cautions that interpreting social network characteristic as social support may be problematic. For example, a larger social network may infer more opportunities for social support but may also increase demands on the individual and increase the potential for negative support (Stokes, 1983). Toohey et al.'s (2004) results also contracted the correlation between social networks and social support. They found that when comparing homeless and housed women, there were no differences in network size but there were group differences in the quality and amount of support provided by the networks (2004). This points to the complexities of social support and the need to consider the quality of the support offered (Rook, 1984). The homelessness literature has further highlighted the complexities and potential for harm from social relationships (Karabanow, 2008; Tessler et al., 2001). Examining both social support and social networks provides a more comprehensive lens from which to understand the link between social relationships and housing, and the quality of these relationships.

The current literature suggests that social support and housing situations are connected; differences between housed and homeless women's social support and social network characteristics imply that housing is a contributing influence (Anderson \& Rayens, 2004; Kennedy, 2007; Shinn et al., 1991; Tavecchio et al., 1999; Toohey et al., 2004; Votta \& Farrell, 2009). However, these studies have failed to consider vulnerably housed women, who show more similarities to homeless women than stably housed individuals (Hwang et al., 2011). Understanding the differences between homeless and vulnerably housed women's social relationships would provide further evidence for this connection and has implications for this population's well-being.

\section{The Current Study}

This study aimed to compare homeless and vulnerably housed women's social networks and social support, exploring (1) the composition and size of social networks of homeless and vulnerably housed women, (2) the kinds of social support that homeless and vulnerably housed women receive from their networks, and (3) predictors of social support in homeless and vulnerably housed women.

\section{METHODS}

Participants. Participants were recruited through women's emergency shelters, supportive housing, and drop-in centres (see Table 1 for breakdown). Convenience sampling methods were used to recruit participants on-site. Staff at each location announced the study and facilitated in-person introductions to 
the researcher, who then screened potential participants. Participants were interviewed at each location until there were no longer any interested individuals who met the criteria or until the projected sample size was reached. Homelessness was operationally defined as anyone who is currently staying in an emergency shelter, sleeping outside, or couch surfing (staying with a family member/friend for less than 1 month) for at least 7 days (Hwang, 2011). Vulnerably housed individuals were included if they have moved at least twice in the past 12 months or experienced an episode of homelessness in the past 12 months (Holton, Gogosis, \& Hwang, 2010). All participants were over 18 years of age and voluntarily consented to participate in the study. This study was reviewed and approved by the University of Ottawa's Research Ethics Board and followed all ethical protocols for research involving humans. A total of 93 women participated in one-on-one English interviews (49 homeless and 44 vulnerably housed).

Table 1

Recruitment Locations

\begin{tabular}{lrrr}
\hline Location (Organization) & Total & Homeless & Vulnerably Housed \\
\hline Emergency shelter & 45 & 40 & 5 \\
Supportive housing & 20 & 1 & 19 \\
Drop-in centre & 27 & 8 & 19 \\
Other & 1 & 0 & 1 \\
Total participants & 93 & 49 & 44 \\
\hline
\end{tabular}

\section{Measures}

Social Network Measures. The Hierarchical Mapping Technique (HMT) employs a concentric circles diagram to facilitate collection of social network information (Antonucci, 1986). Participants were asked to name and place members of their social network on the three circles relative to how close they feel to them. Follow-up questions about each network member included their relationship to the participant, homeless network members, frequency of contact, length of time known to participant, and proximity to participant. Because this measure has been uniquely adapted to fit each study, reliability and validity measures were not available; however, all studies spoke of the frequent and successful use of this measure with varying populations (Ajrouch, Blandon, \& Antonucci, 2005; Harlow \& Cantor, 1994; Antonucci, Lansford, \& Akiyama, 2001).

Social Support Network. The Arizona Social Support Interview Schedule (ASSIS) is a combined social support and social network measure (Barrera, 1980). Participants named individuals in their networks who provided support in six domains: intimate interactions, material aid, advice, positive feedback, physical assistance, and social participation (Barrera, 1980). Participants were also asked how satisfied they are with the support they received, and the perceived level of support needed for each of the six domains (Barrera, 1980). A sum of supportive network members was calculated for each type of support along with a total 
support networks score. Need for support and satisfaction with support were averaged over the six types of support. Reliability tests offer varied results on this measure; test-retest correlation of social network size was .88 and negative interactions network was .54. Satisfaction scales showed a Cronbach's Alpha of .69, (Barrera, 1980).

Global Social Support. The Multidimensional Scale of Perceived Social Support (MSPSS) is a 12-question measure of global social support, measured on a 7-point Likert scale. A higher score indicated higher levels of perceived social support (Zimet, Dahlem, Zimet, \& Farley, 1988). Reliability indicators show good internal consistency $(\alpha=.88)$ and retest reliability was satisfactory ( $\alpha=.84$ to .92 ; Zimet et al, 1988; Zimet, Powell, Farley, Werkmen, \& Berkoff, 1990).

Demographics. Participants self-reported the number of months in their current housing situation and their number of homeless episodes. They were also asked if they had any diagnosed mental or physical health problems, coded as yes or no responses. Finally, demographic questions included age, race/ethnicity, level of education, employment status, and marital status.

Procedure. Participants were recruited with the help of staff at each of the recruitment locations. Participants responded to all three measures during one-on-one interviews, beginning with the HMT, and followed by the ASSIS, the MSPSS and demographic questions. Participants averaged 28 minutes to complete the interview.

Analysis. Missing data was calculated at less than 5\% of all data collected and therefore, any missing values were deleted pairwise in all calculations. Homeless $(n=49)$ and vulnerably housed $(n=44)$ groups were compared using chi-squared and $t$-test analyses. Two multiple linear regressions were completed to test the predictive ability of social network characteristics and demographic variables on social support scores. Housing type was entered first as a control. All other variables were entered together in a second step. The second regression tested the predictability of social network and social support characteristics for global social support scores. Again, housing type was entered as the initial step, followed by independent variables in the second step. All analyses were evaluated with a $p$ value of .05.

\section{RESULTS}

\section{Demographics}

Demographics are presented in Table 2. When comparing demographic characteristics by housing type, very few differences were found. Homeless and vulnerably housed participants differed only on their rates of physical health problems, with the vulnerably housed group having higher rates of physical health problems than the homeless group $\left[\chi^{2}(1, N=93)=6.43, p=.01\right]$. All other demographics did not differ by housing type.

\section{Social Network Characteristics}

Overall participants reported an average social network size of 7 people (see Table 3 ). Vulnerably housed and homeless women did not differ on their social network size. However, vulnerably housed women 
Table 2

Demographics

\begin{tabular}{|c|c|c|c|c|c|}
\hline Variable & $\begin{array}{l}\text { Total } \\
(N=93)\end{array}$ & $\begin{array}{l}\text { Homeless } \\
(n=49)\end{array}$ & $\begin{array}{l}\text { Vulnerably } \\
\text { Housed } \\
(n=44)\end{array}$ & $\begin{array}{l}\chi^{2} \\
(\mathrm{a}=t \text { score })\end{array}$ & $p$ \\
\hline Age (SD) & $38(13.5)$ & $37(13.3)$ & $40(13.8)$ & $-0.91^{a}$ & .365 \\
\hline Ethnicity (\%) & & & & 8.34 & .214 \\
\hline Aboriginal & 16 & 21 & 10 & & \\
\hline White & 56 & 50 & 63 & & \\
\hline Black & 3 & 6 & 0 & & \\
\hline Latin American & 3 & 0 & 5 & & \\
\hline Mix & 23 & 23 & 23 & & \\
\hline Education $(\%)$ & & & & 1.65 & .647 \\
\hline Elementary School & 14 & 19 & 9 & & \\
\hline Some High School & 46 & 44 & 49 & & \\
\hline Completed High School & 9 & 8 & 9 & & \\
\hline Postsecondary & 31 & 29 & 33 & & \\
\hline Currently Employed (\% Yes) & 12 & 10 & 14 & 0.31 & .580 \\
\hline Children (\% Yes) & 58 & 53 & 63 & 0.89 & .346 \\
\hline Marital Status (\%) & & & & 0.82 & .936 \\
\hline Single & 65 & 65 & 66 & & \\
\hline Married/Common Law & 12 & 15 & 9 & & \\
\hline Divorced & 19 & 17 & 21 & & \\
\hline Widowed & 4 & 4 & 5 & & \\
\hline Number of Homeless Episodes ( $S D$ ) & $\begin{array}{l}3.7 \\
(7.1)\end{array}$ & $\begin{array}{l}4.0 \\
(9.1)\end{array}$ & $\begin{array}{l}3.4 \\
(4.0)\end{array}$ & $0.39^{\mathrm{a}}$ & .695 \\
\hline Physical Health Problems (\% Yes) & 59 & 46 & 72 & $6.43 *$ & $.011^{*}$ \\
\hline Mental Health Problems (\% Yes) & 56 & 52 & 61 & 0.65 & .421 \\
\hline
\end{tabular}

$* p<.05$ 
reported a lower percentage of homeless network members $[t(86)=2.91, p=.005,95 \% \mathrm{CI}(0.45,0.24), d$ $=0.55]$ and fewer other family members $[t(90)=1.96, p=.045,95 \% \mathrm{CI}(0.01,0.97), d=0.44]$. There were no differences in proximity to network, amount of contact, or length of time knowing network members by housing type.

\section{Social Support Network}

Overall, participants reported nine individuals in their social support network (see Table 4). Vulnerably housed women had significantly smaller social support networks $[t(90)=2.10, \mathrm{p}=.039,95 \% \mathrm{CI}(0.09,3.19)$, $d=0.43]$ and had accessed fewer support network members in the last 30 days $[t(90)=2.35, p=.021$, $95 \% \mathrm{CI}(0.24,2.89), d=0.46]$ than homeless women. When comparing types of support, vulnerably housed women showed smaller support networks for positive feedback $[t(85)=2.60, \mathrm{p}=.011,95 \% \mathrm{CI}(0.17,1.29)$, $d=0.51]$ and social participation $[t(85)=2.64, \mathrm{p}=.010,95 \% \mathrm{CI}(0.17,1.24), d=0.52]$ than homeless women. Intimate interactions, material aid, advice, physical assistance and negative interactions did not differ by housing type. However, when asked about their need for support, vulnerably housed women reported a significantly lower need for support than homeless women $[t(90)=2.03, p=.045,95 \% \mathrm{CI}(0.01,0.89), d=$ 0.48]. There was no difference in satisfaction with support or global social support by housing type.

\section{PREDICTING GLOBAL SOCIAL SUPPORT}

Two linear multiple regressions were conducted to determine predictors of global social support. The data met all assumptions and no multicollinearity was found between variables. The first linear regression tested demographic variables and their relationship to social support while controlling for housing status (see Table 5). The overall model was significant at $F(13,68)=2.139, p=.022$. The model predicted $29 \%$ of the variance between demographics and social support scores $\left(\mathrm{R}^{2}=.29, f^{2}=0.41\right)$. Within the regression, age was found to be significant, with younger participants reporting higher social support scores $[\beta=-.392$, $t=-2.524, p=.014,95 \% \mathrm{CI}(-0.70,-0.08)]$. Marital status also predicted global social support with married and widowed/divorced participants reporting significantly higher social support scores than those who are single $[\beta=.299, t=2.686, p=.009,95 \% \mathrm{CI}(3.64,24.71) ; \beta=.397, t=3.046, p=.003,95 \% \mathrm{CI}(5.03,24.11)]$. All other demographic variables were not significant.

A second linear regression tested social networks and social support networks on their ability to predict global social support (see Table 6). The overall model was significant at $F(11,72)=3.270, p=.001$ and predicted $35 \%$ of the variance $\left(\mathrm{R}^{2}=.35, f^{2}=0.55\right)$. Larger social support networks predicted higher global social support scores $[\beta=.499, t=4.463, p<.001,95 \% \mathrm{CI}(1.12,2.92)]$. For overall frequency of contact, one dummy code was significant with participants who average monthly contact with their networks reporting lower social support scores than those who had daily contact $[\beta=-.389, t=-2.572, p=.012,95 \% \mathrm{CI}$ $(-21.24,-2.69)]$. However, yearly contact compared to daily contact was not significant $[\beta=-.10 .605, t=$ $-1.426, p=.158,95 \%$ CI $(-25.43,-4.22)]$. None of the other tested variables were significant in this model. 


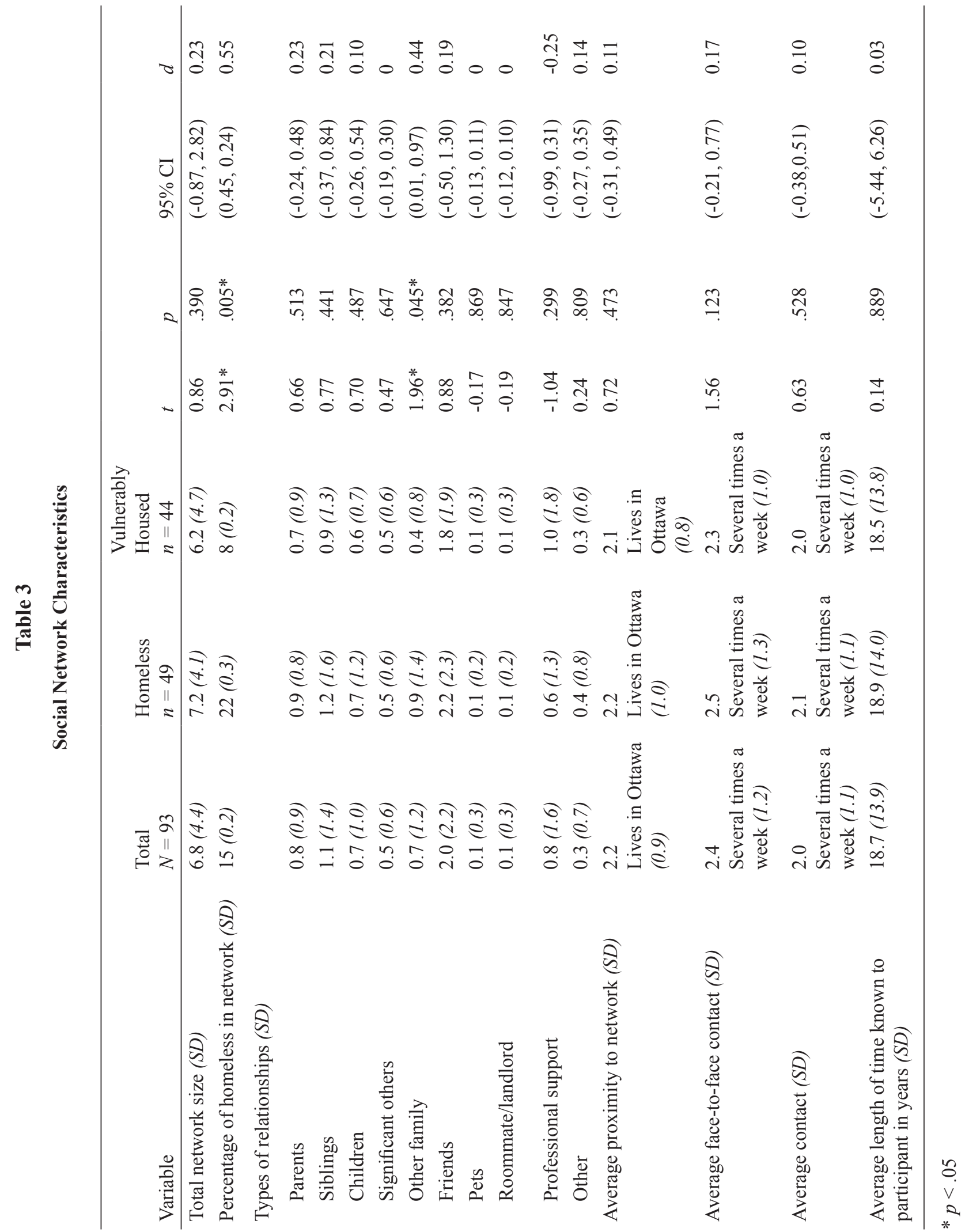




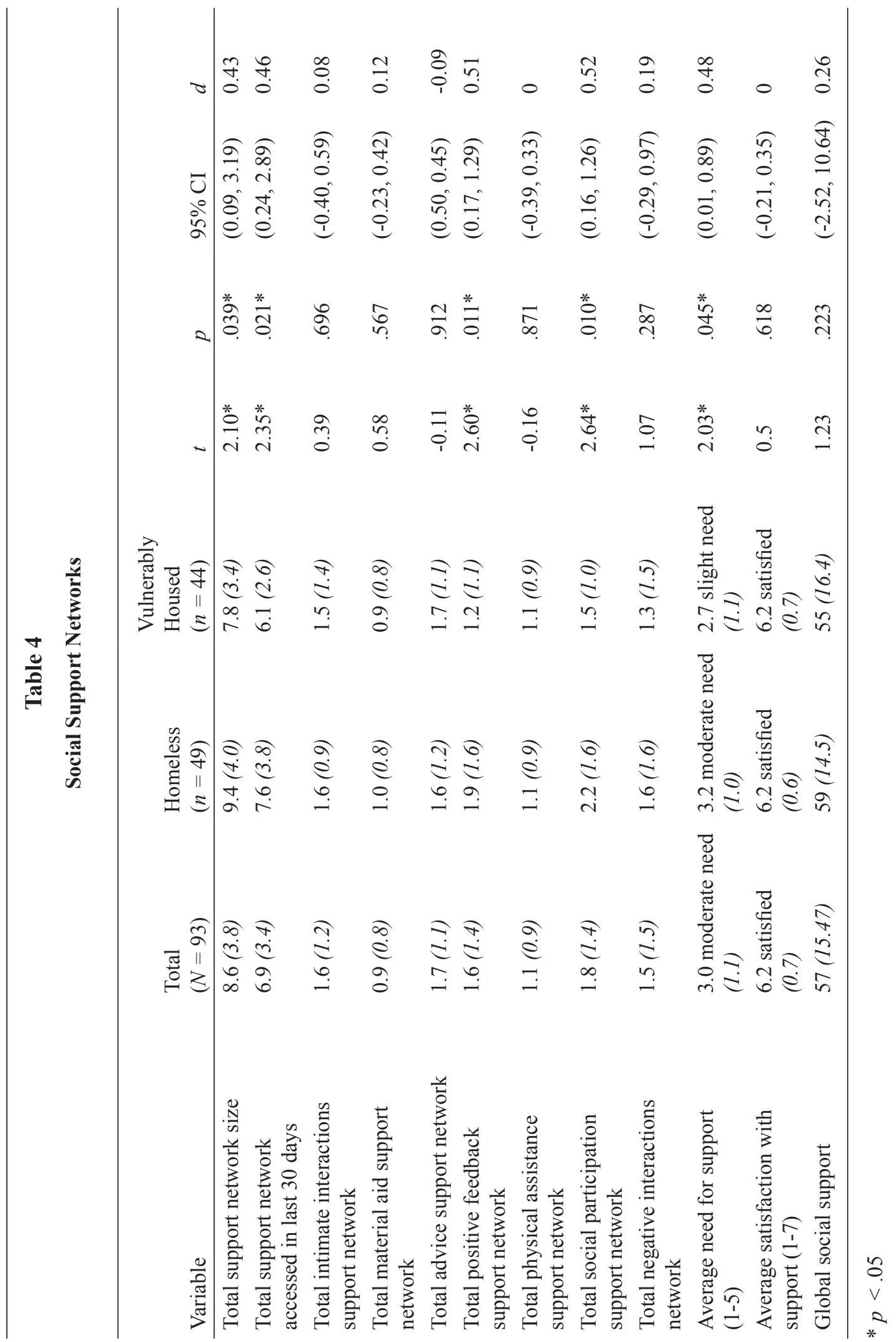


Table 5

Linear Regression Predicting Global Social Support Scores by Demographic Variables

\begin{tabular}{|c|c|c|c|c|c|}
\hline Variable & $\mathrm{B}(\mathrm{U})$ & $\beta(S)$ & $T$ & $p$ & $95 \% \mathrm{Cl}$ \\
\hline Housing status & -2.419 & -0.078 & -0.695 & .490 & $(-9.37,4.53)$ \\
\hline Age & -0.392 & -0.343 & $-2.524^{*}$ & $.014 *$ & $(-0.70,-0.08)$ \\
\hline \multicolumn{6}{|l|}{ Ethnicity } \\
\hline Aboriginal vs. white & 3.163 & 0.095 & 0.859 & .394 & $(-4.19,10.51)$ \\
\hline Black vs. white & -2.453 & -0.043 & -0.369 & .713 & $(-15.71,10.80)$ \\
\hline Other vs. white & -0.821 & -0.012 & -0.108 & .914 & $(-16.00,14.36)$ \\
\hline \multicolumn{6}{|l|}{ Marital status } \\
\hline Married vs. single & 14.179 & 0.299 & $2.686^{*}$ & $.009 *$ & $(3.64,24.71)$ \\
\hline Widowed/divorced vs. single & 14.569 & 0.397 & $3.046^{*}$ & $.003 *$ & $(5.03,24.11)$ \\
\hline \multicolumn{6}{|l|}{ Education } \\
\hline $\begin{array}{l}\text { Completed vs. not completed } \\
\text { high school }\end{array}$ & -7.104 & -0.129 & -1.179 & .242 & $(-19.13,4.91)$ \\
\hline $\begin{array}{l}\text { Postsecondary vs. not } \\
\text { completed high school }\end{array}$ & 5.465 & 0.163 & 1.414 & .162 & $(-2.25,13.18)$ \\
\hline Children & 575 & 0.018 & 0.14 & .889 & $(-7.64,8.79)$ \\
\hline Number of homeless episodes & -0.324 & -0.149 & -1.404 & .165 & $(-0.79,0.14)$ \\
\hline Physical health problems & -0.459 & -0.015 & -0.12 & .905 & $(-8.06,7.15)$ \\
\hline Mental health problems & -6.636 & -0.214 & -1.766 & .082 & $(-14.13,0.86)$ \\
\hline
\end{tabular}

$* \mathrm{p}<.05$ 
Table 6

Linear Regression Predicting Global Social Support Scores by Social Network and Social Support Variables

\begin{tabular}{llllll}
\hline Variable & $\mathrm{B}(\mathrm{U})$ & $(\mathrm{S})$ & $t$ & $p$ & $95 \% \mathrm{CI}$ \\
\hline Housing status & 0.429 & 0.014 & 0.136 & .892 & $(-5.87,6.73)$ \\
Length of time knowing network & 0.014 & 0.151 & 1.318 & .192 & $(-0.01,0.04)$ \\
$\begin{array}{l}\text { Face to face contact with network } \\
\quad\end{array}$ & & & & & \\
$\quad$ Monthly vs. daily & 3.561 & 0.114 & 0.663 & .509 & $(-7.14,14.26)$ \\
$\quad$ Yearly vs. daily & 4.546 & 0.113 & 0.553 & .582 & $(-11.85,20.95)$ \\
Contact with network & & & & & \\
$\quad$ Monthly vs. daily & -11.965 & 0.389 & $-2.572^{*}$ & $.012^{*}$ & $(-21.24,-2.69)$ \\
$\quad$ Yearly vs. daily & -10.605 & 0.217 & -1.426 & .158 & $(-25.43,4.22)$ \\
Proximity to network & & & & & \\
$\quad$ Nearby vs. in Ottawa & -0.925 & 0.020 & -0.187 & .852 & $(-10.78,8.93)$ \\
$\quad$ Elsewhere vs. in Ottawa & 3.409 & 0.070 & 0.502 & .617 & $(-10.13,16.95)$ \\
Total network size (HMT) & 0.099 & 0.028 & 0.254 & .800 & $(-0.68,0.88)$ \\
Total support network size (ASSIS) & 2.016 & 0.499 & $4.463 *$ & $<.001^{*}$ & $(1.12,2.92)$ \\
Need for support & -0.145 & 0.010 & -0.093 & .926 & $(-3.25,2.96)$ \\
Satisfaction with support & 1.850 & 0.081 & 0.761 & .446 & $(-3.00,6.70)$ \\
\hline
\end{tabular}

$* \mathrm{p}<.05$ 


\section{DISCUSSION}

This study aimed to understand the social support and social networks of homeless and vulnerably housed women. Examining these relationships offers a more comprehensive view of how social relationships are linked to housing vulnerability and has implications for well-being.

\section{Demographics}

When comparing vulnerably housed and homeless samples, there were few differences in their demographics. Non-parametric tests showed the presence of physical health problems differed by housing group, with more vulnerably housed women reporting physical health problems than homeless women. This difference may be explained by the sampling method used for vulnerably housed participants; these participants were recruited from supportive housing locations that prioritize individuals with health needs, potentially inflating the difference between homeless and vulnerably housed groups. All other demographic characteristics were comparable and suggest that homeless and vulnerably housed women are similar populations. Knowing these sample similarities gives further evidence that the group differences reported in this study are more likely due to their housing differences than their demographic differences.

In the regression analysis, only two demographic variables were significant: age and marital status. Younger participants reported higher levels of global social support than older participants, similar to other studies on age differences in social support (Lincoln, Chatters, \& Taylor, 2005; Siedlecki, Salthouse, Oishi, \& Jeswani, 2014; Vaux, 1985). Also, married and widowed/divorced participants perceived more support than single participants. This indicates homeless and vulnerably housed women who are older and single are especially in need of support services and opportunities to increase their social support.

Surprisingly, physical and mental health impairments did not predict social support. There is a strong connection in the literature between health and social support in low-income populations (Durden et al., 2007; Israel et al., 2002; Tucker et al., 2005; Turner et al., 2008). However, mental and physical health were measured as a dichotomous variable (i.e., the presence or absence of a physical or mental illness diagnosis), which may have limited their predictive ability. This does imply that the link between health and social support is complex and further research is needed to better understand this relationship.

\section{Social Network Characteristics}

Social network characteristics showed similarities between homeless and vulnerably housed samples; homeless and vulnerably housed women reported similar social network sizes. Key differences between the groups emerged in the proportion of homeless individuals. It is not surprising that vulnerably housed women report fewer homeless social network members than homeless women. Although the quantitative literature has not looked at this variable, Klitzing (2004) found that homeless women were closely connected to other homeless women through their use of the shelter system. However, as the majority of this sample was previously homeless, it may be an indication that friendships made during the time spent homeless are temporary and dissolve once the individual is housed. More research into housing trajectories and their impact on social networks is needed to draw further conclusions. 


\section{Social Support Networks}

This study also explored social support networks and types of social support. Vulnerably housed women reported significantly fewer supportive individuals in their social support networks than homeless women. This trend was also seen with social support networks accessed in the last 30 days. This contradicts Goodman's (1991) findings that reported no difference in social support networks between homeless and housed families using the same measure. This also highlights the differences between social networks (i.e., socially connected individuals) and social support networks (i.e., network members who provide support). Although both samples reported similar social network sizes, vulnerably housed women had fewer network members that provided support. The difference in social support network size combined with the finding that social support networks predict global social support suggests that there is a deficit of social support for women experiencing housing vulnerability in comparison to those who are homeless. This is an opportunity for service providers to increase the accessibility and availability of support services for vulnerably housed women as a way to indirectly improve their well-being.

Overall, participants reported larger social support networks than social networks, raising questions about the differences in these two constructs. Further exploration of these measures found significantly more professionals and fewer family members reported in the social support networks than in social networks. In this sample, support needs are more likely to be met by service providers than informal supports, and service providers were less likely to be considered members of their social networks. This finding proposes that homeless and vulnerably housed women perceive social networks and social support networks to be different groups of people. Further exploration of these constructs is needed to determine if these findings reflect measurement differences or this population's experiences of social relationships.

Of the six types of social support, vulnerably housed women reported smaller networks in positive feedback or social participation support compared to homeless women. This is a unique finding, as studies using this measure with low-income populations have not considered these specific types of support in their analysis. Interpreting the differences found in positive feedback support is challenging as there is no obvious link between the experiences of these housing differences and these specific types of social support. Differences in social participation networks could be due to the configuration of housing types; women living in shelters have more opportunities to socialize with others who are sharing their accommodations in comparison to women who are living in independent housing. Further research is needed to explore and understand these differences.

Vulnerably housed women reported less need for support compared to homeless women. This may be reflective of the different housing situations and the importance of having housing. When immediate housing needs are addressed, the need for support decreases.

Both homeless and vulnerably housed groups reported high global social support scores. Although vulnerably housed women reported smaller social support networks, their lower need for social support may moderate their perceptions of global social support, resulting in similar scores. These findings highlight further avenues of research into how social networks, social support networks, and global social support relate to each other. 


\section{LIMITATIONS}

There are two main limitations to this study. First, this study used convenience sampling methods to recruit participants. Although this was a realistic method considering the challenges of recruiting these populations, it may have overlooked sub-populations of homeless individuals that do not access local service organizations. It also impacted the distribution of vulnerably housed women who were recruited from supportive housing living situations in comparison to independent housing. Other housing differences within these groups may limit the interpretability of these results. By combining varying housing situations (e.g., supportive housing, rooming houses, living with roommates) within the vulnerably housed sample, it may have overlooked further differences in the link between housing and social support. Furthermore, the length of time the sample had lived in their current housing situation may have influenced their social support experiences in relation to their housing.

Secondly, these results were also impacted by the limitations of the measures chosen. All measures employed in this study were based on self-report, creating a potential for inaccuracy and recall bias. Quantitative measurement also limited the findings, focusing on predetermined variables and limiting the ability to assess the complexities of social relationships. Qualitative measurement would allow for a more in-depth and open exploration of the nuances of these experiences. Thirdly, this study has low power due to a small sample size. Low power increases the chance of a type II error and can reduce generalizeability of the results. This study was exploratory, and a starting point for further research into social support and social networks in this population. However, low power limits the application of these results and suggests caution when generalizing this research to similar populations.

\section{CONCLUSIONS AND IMPLICATIONS OF FINDINGS}

These findings support the link between housing and social relationships. Significant differences between homeless and vulnerably housed women's social support networks gives further evidence to corroborate the link between housing status and social support. However, research is still needed to understand specific housing contexts and how they influence social support experiences. Also, exploring housing transitions and how they impact social support would help identify the needs of women exiting homelessness into housing. By having a more comprehensive understanding of social support and housing, further research can now

explore how these variables relate to well-being and how housing service providers can support better mental health and stress reduction through efforts to build social support.

\section{REFERENCES}

Ajrouch, K., Blandon, A., \& Antonucci, T. (2005). Social networks among men and women: The effects of age and socioeconomic status. Journal of Gerontology, 60B(6), S311-S317.

Alliance to End Homelessness. (2016). Progress report on ending homelessness. Ottawa: Alliance to End Homelessness. Anderson, D., \& Rayens, M. (2004). Factors influencing homelessness in women. Public Health Nursing, 21(1), 12-23. Antonucci, T. (1986). Hierarchical Mapping Technique. Generations: Journal of the American Society on Aging, 10(4), $10-12$.

Antonucci, T., Lansford, J., \& Akiyama, H. (2001). Impact of positive and negative aspects of marital relationships and friendships on well-being of older adults. Applied Developmental Science, 5(22), 68-75. 
Aubry, T., Klodawsky, F., Hay, E., \& Birnie, S. (2003). Panel study on persons who are homeless in Ottawa: Phase 1 results. Ottawa: Centre for Research on Community Services.

Barrera, M. (1980). A method for the assessment of social support networks in community survey research. Connections, 3, 8-13.

Brenner, G., Norvell, N., \& Limacher, M. (1989). Supportive and problematic social interactions: A social network analysis. American Journal of Community Psychology, 17(6), 831-837.

Bui, H., \& Morash, M. (2010). The impact of network relationships, prison experiences, and internal transformation on women's success after prison release. Journal of Offender Rehabilitation, 49(1), 1-22.

Canadian Homelessness Research Network. (2012). Canadian definition of homelessness. Retrieved from http://www. homelesshub.ca/sites/default/files/COHhomeless definition.pdf.

Cheng, T., Wood, E., Feng, C., Mathias, S., Montaner, J., Kerr, T., \& DeBeck, K. (2013). Transitions into and out of homelessness among street-involved youth in a Canadian setting. Health \& Place, 23, 122-127.

Cohen, C., Ramirez, M., Teresi, J., Gallagher, M., \& Sokolovsky, J. (1997). Predictors of becoming redomiciled among older homeless women. The Gerontologist, 37(1), 67-74.

Curley, A. (2009). Draining or gaining? The social networks of public housing movers in Boston. Journal of Social and Personal Relationships, 26, 277-247.

Durden, E., Hill, T., \& Angel, R. (2007). Social demands, social supports and psychological distress among low-income women. Journal of Social and Personal Relationships, 24, 343-361.

Gaetz, S., Gulliver, T., \& Richter, T. (2014). The state of homelessness in Canada 2014. Toronto: The Homeless Hub Press.

Goodman, L. (1991). The relationship between social support and family homelessness: A comparison study of homeless and housed mothers. Journal of Community Psychology, 19, 321-332.

Haines, V., Beggs, J., \& Hurlbert, J. (2008). Contextualizing health outcomes: Do effects of network structure differ for women and men? Sex Roles, 59, 164-175.

Harlow, R., \& Cantor, N. (1994). Social pursuits of academics: Side-effects and spillover of strategic reassurance seeking. Journal of Personality and Social Psychology, 66(2), 386-397.

Holton, E., Gogosis, E. \& Hwang, S. (2010). Housing vulnerability and health: Canada's hidden emergency. Toronto: Research Alliance for Canadian Homelessness, Housing and Health.

Hwang, S. (2011, October). Health care utilization among people who are homeless. In Without a home: Research symposium on contemporary issues in Canadian homelessness. Symposium conducted at York University, Toronto, Canada.

Hwang, S., Aubry, T., Palepu, A., Farrell, S., Nisenbaum, R., Hubley, A....Chambers, C. (2011). The health and housing in transition study: A longitudinal study of the health of homeless and vulnerably housed adults in three Canadian cities. International Journal of Public Health, 56, 609-625.

Israel, B., Farquhar, S., Schulz, A., James, S., \& Parker, E. (2002). The relationship between social support, stress, and health among women on Detroit's East Side. Health, Education \& Behavior, 29, 342-358.

Karabanow, J. (2008). Getting off the street: Exploring the processes of Young People's Street exits. American Behavioral Scientist, 51, 772-788.

Kennedy, A. (2007). Homelessness, violence, exposure, and school participation among urban adolescent mothers. Journal of Community Psychology, 35(5), 639-654.

Kleit, R. (2010). Draining ties: Tie quality versus content in low-income women's social networks when displaced by redevelopment. Journal of Social and Personal Relationships, 27, 573-588.

Klitzing, S. (2004). Women who are homeless: Leisure and affiliation. Therapeutic Recreation Journal, $38(4), 348-365$.

Klodawsky, F. (2006). Landscapes on the margins: Gender and homelessness in Canada. Gender, Place \& Culture, 13(4), 365-381.

Lincoln, K., Chatters, L., \& Taylor, R. (2005). Social support, traumatic events, and depressive symptoms among African Americans. Journal of Marriage and Family, 67(3), 754-766.

Lyon, D., Dooley, S., \& Gagnon, N. (2014). The homeless and the vulnerably housed in Surrey: Exploring variations in needs and experiences. Retrieved from http://www.surrey.ca/files/Homeless_and_Vulnerably_Housed_in_ Surrey_-_KPU.pdf 
McQuistion, H. L., Gorroochurn, P., Hsu, E., \& Caton, C. L. (2014). Risk factors associated with recurrent homelessness after a first homeless episode. Community Mental Health Journal, 50(5), 505-513.

Novac, S., Brown, J., \& Bourbonnais, C. (1996). No room of her own: A literature review on homelessness. Canadian Mortgage and Housing Corporation.

Rook, K. (1984). The negative side of social interaction: Impact on psychological well-being. Journal of Personality and Social Psychology, 46(5), 1097-1108.

Sarason, I., Levine, H., Basham, R., \& Sarason, B. (1983). Assessing social support: The social support questionnaire. Journal of Personality and Social Psychology, 44(1), 127-139.

Segaert, A. (2012). The national shelter study: Emergency shelter use in Canada 2005-2009. Homelessness Partnering Strategy.

Siedlecki, K., Salthouse, T., Oishi, S., \& Jeswani, S. (2014). The relationship between social support and subjective well-being across age. Social Indicators Research, 117, 561-576.

Shinn, M., Knickman, J., \& Weitzman, B. (1991). Social relationships and vulnerability to becoming homeless among poor families. American Psychologist, 46(11), 1180-1187.

Stokes, J. (1983). Predicting satisfaction with social support from social network structure. American Journal of Community Psychology 11(2), 141-152.

Tavecchio, L., Thomeer, E., \& Meeus, W. (1999). Attachment, social network, and homelessness in young people. Social Behaviour and Personality, 27(3), 247-262.

Tessler, R., Rosenheck, R., \& Gamache, G. (2001). Gender differences in self-reported reasons for homelessness. Journal of Social Distress and the Homeless, 10(3), 243-254.

Thoits, P. (2010). Stress and health: Major findings and policy implications. Journal of Health and Social Behaviour, $51(1), \mathrm{S} 41-53$.

Toohey, S., Shinn, M., \& Weitzman, B. (2004). Social networks and homelessness among women heads of household. American Journal of Community Psychology, 33(1/2), 7-20, 35-43.

Tucker, J., D’Amico, E., Wenzel, S., Golinelli, D, Elliott, M., \& Williamson, S. (2005). A prospective study of risk and protective factors for substance use among impoverished women living in temporary shelter settings in Los Angeles County. Drug and Alcohol Dependence, 80, 35-43.

Turner, L., Mermelstein, R., Hitsman, B, \& Warnecke, R. (2008). Social support as a moderator of the relationship between recent history of depression and smoking cessation among lower-educated women. Nicotine \& Tobacco Research, 10(1), 201-212.

Tyler, K. (2008). Social network characteristics and risky sexual and drug related behaviors among homeless young adults. Social Science Research, 37, 673-685.

Vaux, A. (1985). Variations in social support associated with gender, ethnicity and age. Journal of Social Issues, 41(1), 89-110.

Votta, E., \& Farrell, S. (2009). Predictors of psychological adjustment among homeless and housed female youth. Journal of Canadian Academic Child \& Adolescent Psychiatry, 18(2), 126-132.

Zimet, G., Dahlem, N., Zimet, S., \& Farley, G. (1988). The multidimensional scale of perceived social support. Journal of Personality Assessment, 52(1), 30-41.

Zimet, G., Powell, S., Farley, G., Werkmen, S., \& Berkoff, K. (1990). Psychometric characteristics of the Multidimensional Scale of Perceived Social Support. Journal of Personality Assessment, 55(3-4), 610-617. 